\title{
PECULIARITIES OF THE COMMUNICATIVE-SPEECH COMPETENCES OF THE INFANTS WITH DEVIATIONS IN LANGUAGE DEVELOPMENT
}

\author{
M.V. Kimmel ${ }^{1}$, E. Sheremetyeva ${ }^{2}$, O.I. Kovaleva ${ }^{3}$, I. Menendez Pidal ${ }^{4}$ \\ ${ }^{1}$ Municipal Budget Preschool Educational Institution Kindergarten №307 of \\ Chelyabinsk (RUSSIAN FEDERATION) \\ ${ }^{2}$ Pedagogical Institute. Chelyabinsk University (RUSSIAN FEDERATION) \\ ${ }^{3}$ Linguistics Faculty. South Ural State University (RUSSIAN FEDERATION) \\ ${ }^{4}$ Universidad Politécnica de Madrid (SPAIN)
}

\begin{abstract}
Only in the process of communication it is possible to find means which are necessary for interaction. Primary nonverbal means of establishing communicative interaction are improving in continuous practice of communication. Non-verbal means of communication are developing and are improving through communicative gestures and as the add-in under already formed means of communication, the words appear - the first means of verbal communication. Thus, communication with close adults provides the formation of the communicative - speech competences of children. This understanding of the ontogeny of the formation of the communicative-speech competences allows us to draw a conclusion about the gradual displacement of non-verbal means of verbal communication. Moreover, these non-verbal means of communication do not disappear, but they are transferred from fixed assets in the subsidiary. In the context of the studied theme: the communicatively-speech competences of children of early ages are non-verbal and verbal means of interaction with close adults and the methods of their usage with the purpose of reaching the appearing of household, gaming, cognitive and creative needs. To achieve the aim of exploring we used the methods of diagnostics of psycho-speech development of the child of early ages (E. V. Sheremetyeva, 2013), which allowed us to make a communicative-speech profile of the child.In the exploring were involved 40 children of the third year of life. On the basis of the obtained data, we can conclude that young children with deviations in language development in contrast to children with normal speech development have not sufficiently formed communicative-speech competences, which negatively affects the productivity of communication. The information of our experimental exploring is the basis for development of complex methods and methods of psychological and pedagogical support of the formation of communicative and speech competences of children with deviations in language development.
\end{abstract}

Keywords: children of early ages, language development, deviations in speech development, communicative language competence, means of communication, socialization.

\section{INTRODUCTION}

A person being a social creature, from the first months of life feels the need to communicate with other people, and this need is constantly growing - from the need for emotional contact to a deep personal communication and collaboration, since communication is a key process, determining the development of personality in these socio-cultural conditions. This fact determines the potential continuation of communication as a necessary condition of life.

Only in the process of communication it is possible to find means which are necessary for interaction (L.S. Vygotsky, M. I. Lisina, A. G. Ruzsky, and E.O. Smirnova). Primary non-verbal means of establishing communicative interaction (head turning towards the speaker, looking in the eyes, "mimic" attention, voice vocalization, etc.) are improving in continuous practice of communication. Then, the first random acts of "speaking" baby appear (goo- goo, syllabic babbling, etc.). Close adults organize these acts of "speaking" in "dialogs": I talk when you look at me and you are silent, I carefully look at you and listen when you are "talking". Non-verbal means of communication are developing and are improving through communicative gestures and as the add-in under already formed means of communication, the words appear - the first means of verbal communication. Thus, communication with close adults provides the formation of the communicative - speech competences of children. This understanding of the ontogeny of the formation of the communicative-speech competences allows us 
to draw a conclusion about the gradual displacement of non-verbal means of verbal communication. Moreover, these non-verbal means of communication do not disappear, but they are transferring from the main means in the subsidiary.

\section{OBJECTIVES}

In the context of the studied theme: the communicative-speech competences of the infants are nonverbal and verbal means of interaction with close adults and the methods of their usage with the purpose of reaching the appearing of household, gaming, cognitive and creative needs.

The aim of our exploring was to determine the level of formation of communicative-speech competences of the infants with deviations in language development.

\section{METHODOLOGY}

To achieve the aim of exploring we used the methods of diagnostics of psycho-speech development of the infants (E. V. Sheremetyeva, 2013), which allowed us to make a communicative-speech profile of the child. In addition, their medical records were studied (the history of the development of children); also, were conducted: surveys, conversation with parents and caregivers, observing children in the process of implementation of the regime moments and free activities.

The experiment was conducted on the basis of the kindergarten №4 (Kopeisk city district) and the kindergarten № 307 (Central district of Chelyabinsk). In the exploring were involved 40 children of the third year of life. The speech development of 20 children matched the age-related standards and 20 children had the abnormalities in speech development of different severity.

In the process of conducting of psychological-pedagogical research of children were taken into account data of these scientists (L. N. Galiguzova, M. I. Lisina, A. G. Ruzsky, E. O., E. V. Sheremetyeva (2013)) concerning the age peculiarities of children's development of the third year of life. Based on the results of these researches, we had identified the criteria of the communicative skills of children of early ages, they appeared:

- in the ability to make a contact with adults and peers;

- in making a contact initiated by adults and peers;

- in demonstrating of communication requirement (in communication and interaction);

- in reacting adequately to adults and peers;

- in using of verbal means of communication (the degree of development of active speech is any speech appeal, demand, claim, naming the objects, narration of action; the degree of development of passive speech - understanding meanings of words, sentences, different parts of speech; the ability to perform verbal instructions of the adult);

- in using of non-verbal means of communication: kinesics, proxemics, para - and extralinguistics, visual communication, takesika.

The research was conducted in two ways. The first direction was the studying of non-verbal and verbal means of communication with adults, and the second direction - with children.

\section{RESULTS}

As the result of the analysis of communicative-and-speech profiles of children we had received such data. Only 8 out of 20 children showed a sustained interest in communicating with adults, to the joint subject-game actions. 6 children with deviations in language development showed short-time interest to adults. They took the cubes, toys then they smiled, but after some moment they lost interest to them, retreated to the side or began to scatter the cubes. 8 children from the group did not watch in eyes, showed no interest in the game and ran away, they also hid. These children were not focused on evaluation of the adult and if they had the unsuccessful attempts to perform the task, children did not search for the help of the adult, they lost interest, didn't always understand an addressed speech, they simply miffed.

In communicating with peers, 14 children with deviations of speech development showed momentary interest, they smiled, entered the game, but when it was time to give the cube to another child, to 
move, etc. they could start to push, to take away the cube, to threaten, to scream or they lost interest and abandoned the joint activity. There were children (4), who immediately refused to participate in the joint activity. They either watched, or did not show any interest at all.

And as a result, 8 children with deviations of speech development used only non-verbal (expressive mimic) means of communication, 4 children used non-verbal communication and pre-speech means (the exclamations, separate syllables, pointing gestures, etc.).

Based on the obtained data and on previously established criteria of the communicative skills of children of the third year of life, we can conclude that the infants with deviations in language development in contrast to children with normal speech development have not sufficiently formed communicative-speech competence.

Children with deviations in speech development have underdeveloped means of communication of the earlier period, which in turn leads to disruption of formation of motivation and need in communication. Children do not feel the need to cooperate with somebody; they are watching with a detachment the actions of the adults or peers, or they are doing what they want. They can appeal to the adults with any request, to satisfy their momentary needs, but after fulfilling these needs, children have lost the interest to the adults. Children can join in the brief contact (a few seconds) with the peers, but only to solve the actual problem. For example, the specific cube is needed at the moment. But children do not negotiate, using available means of communication, they just have taken the cube from another child. Showing a very short-term interest, children can approach another child to do something in its construction (to move or break) and again to step to the side, watching the result of their actions. It means that these children are silent, shy, indecisive or irritable, what negatively impacts on productivity of communication.

\section{DISCUSSION}

When adults initiated contacts, children with deviations in language development had shown a momentary interest in the joint subject-game actions, they were searching for approval from the adult when performing tasks on the model, rejoiced, clapped their hands, but at the slightest difficulty (including a reason of the limited understanding of the speech of the adult), lost interest in the job, could act with cubes inappropriately (to tap, to throw, to take in mouth, etc.). They did not try to stimulate further cooperation with the help of using available means of communication, immediately stopped the interaction. When the adult attempted to resume the game - they ran away, started whining, became capricious, irritable, they could manifest forms of behavior, and correlated with aggression towards the adult (they started to wave his hands or feet).

They could never join or watch on the side the game, initiated by the peer. If they started to play- they played some time enthusiastically, smiled, looked into eyes of the partner, uttered short exclamations addressed to the peer: "here", "give", "take", etc. But if they had to give the toy or to move, they could show forms of behavior associated with aggression (pushing, pulling out the toy and threatening another child), they also could silently leave, or start crying and leave. It means that there is a lack of sensitivity to the partner, his desires, which also indicate the lack of productive communication.

Thus, we can say that children with developmental disorders of speech have the leading motive of communication with adults and with peers, which connected with the interest in the subject, but not in joint objective activities.

These violations have a negative impact on the process of formation of communicative-speech competence and self-consciousness in general.

\section{CONCLUSION}

Data of our conducted experimental research are the basis for the development of content, range of methods and techniques for psychological and pedagogical support of the formation of communicative-speech competence of the children of early ages with disabilities in the development of speech. Based on the concept of "communicative-speech competence" given to us in the beginning of the article, we see that the basis of the contents of this complex is the work on creation of conditions for mastering of every child by all means of communication on the basis of his actual development, taking into account his zone of proximal development. 


\section{REFERENCES}

[1] Vygotsky, L. S. Psychology / L. S. Vygotsky. - M.: EKSMO - Press, 2000. - 1008 p.

[2] Galiguzova, L. N. Pedagogy early childhood / L. N. Galiguzova, S. Yu. Meshcheryakova S. Y. M.: Vlados, 2007. - 304 p.

[3] Lisina M. I. Problems of ontogenesis of communication / M. I. Lisin. - M.: Pedagogika, 1986. 294 p.

[4] Ruzskaya, A. G., peculiarities of communication between children 2-7 years with adult strangers and friends / by A. G. Ruzskaya // Communication and its influence on the mental development of preschooler: SB. nauch. St. - M.: Rotaprint NII OP APN SSSR, 1974. - S. 41-58.

[5] Sheremetyeva, E. V. Prevention of deviations of speech development in children of early age / E. V. Sheremetyeva. - Moscow: national book centre, 2013. - $168 p$ 